\title{
Spinal dural arteriovenous fistula adjacent to a spinal neurofibroma-a misleading coexistence. Case report
}

\author{
I H Tekkök MD,${ }^{1}$ B Açıkgöz MD PhD,${ }^{2} \mathrm{~T}$ Özgen MD,${ }^{3}$ B Önol MD 4 \\ ${ }^{1}$ Instructor in Neurosurgery, ${ }^{2}$ Associate Professor of Neurosurgery, ${ }^{3}$ Professor of \\ Neurosurgery, ${ }^{4}$ Professor of Pathology, Departments of Neurosurgery and Pathology, \\ Hacettepe University School of Medicine, Sihhiye, Ankara, Turkey.
}

\begin{abstract}
The authors report the case of a patient harbouring a spinal dural arteriovenous fistula adjacent to an intradural neurofibroma. Only the latter could be demonstrated by the diagnostic modalities employed. Such a coexistence proved misleading and two interventions were needed to cure both lesions. Only one report has appeared in the literature dealing with such a condition. The possibility of such a coexistence is stressed and mechanisms are discussed.
Keywords: neurofibroma; spinal dural arteriovenous fistula; spinal intradural neurofibroma; spinal tumour.

\section{Introduction}

A spinal dural arteriovenous fistula (AVF) is a distinct type of spinal arteriovenous malformation (AVM) previously termed as 'single coiled vessel' or 'type I malformation'. It was distinguished as a separate entity by Kendall and Logue in $1977 .{ }^{1}$ Spinal dural AVF is composed of an extradural feeder, a nidus and a draining intradural vein. The nidus is either in the dura near the intervertebral foramen or around the dural sleeve of the dorsal root. Yaşargil et al have defined this type as the most common among spinal AVMs. ${ }^{2}$ The clinical picture is a slowly progressive myelopathy, which should be differentiated from tumours of the spinal cord. ${ }^{3}$ The occurrence of a spinal neoplasm in association with a spinal dural AVF can be quite misleading for both the surgeon and the radiologist since the clinical picture and solid image of a mass will mask the AVF. The purpose of this paper is to present our experience in such a patient harbouring both a spinal dural AVF around the right $\mathrm{T} 9$ dorsal root and an intradural neurofibroma originating from the right $\mathrm{T} 7$ dorsal root. Only one such case with a cervical AVF and a neurofibroma could be

Correspondence: Doçent Dr. Bektaş Açıkgöz, Hacettepe Üniversitesi, Tıp Fakültesi, Beyin Ve Sinir Cerrahisi Anabilim Dalı, Sıhhıe, Ankara 06100, Turkey. traced in the English literature. ${ }^{4}$ This association may be a peculiar clinical presentation which awaits further confirmation.

\section{Case history}

A 20 year old university student presented with right sided band-like chest pain of 3 years' duration. During the last 3 months, he experienced weakness and loss of spatial control in his legs. The past medical and family histories were of no significance.

Neurological examination revealed a spastic paraparesis with a global leg power of antigravity. Sensation to pinprick and light touch was decreased below T10 on the right and T8 on the left. Joint position and vibration senses were absent below the knees. Reflexes were brisk at both knees and ankles. The plantar responses were extensor and there was bilateral ankle clonus. Anal tone was normal with the anal reflex slightly diminished. There was no cutaneous stigmata over the neuroaxis.

Plain xrays of the spine revealed no bony abnormality. An Iohexol myelogram showed a small right sided defect at T8-9 intervertebral foramen level. T1-weighted magnetic resonance (MR) images were not contributory except for demonstrating a minimal enlargement of the spinal cord between $\mathrm{T} 7$ and $\mathrm{T} 9$, but after gadolinium diethylene triamine pentaacetic acid (Gd-DTPA) injection a markedly enhancing mass on the right side of the spinal cord at T8 level (Fig 1) could be demonstrated. 


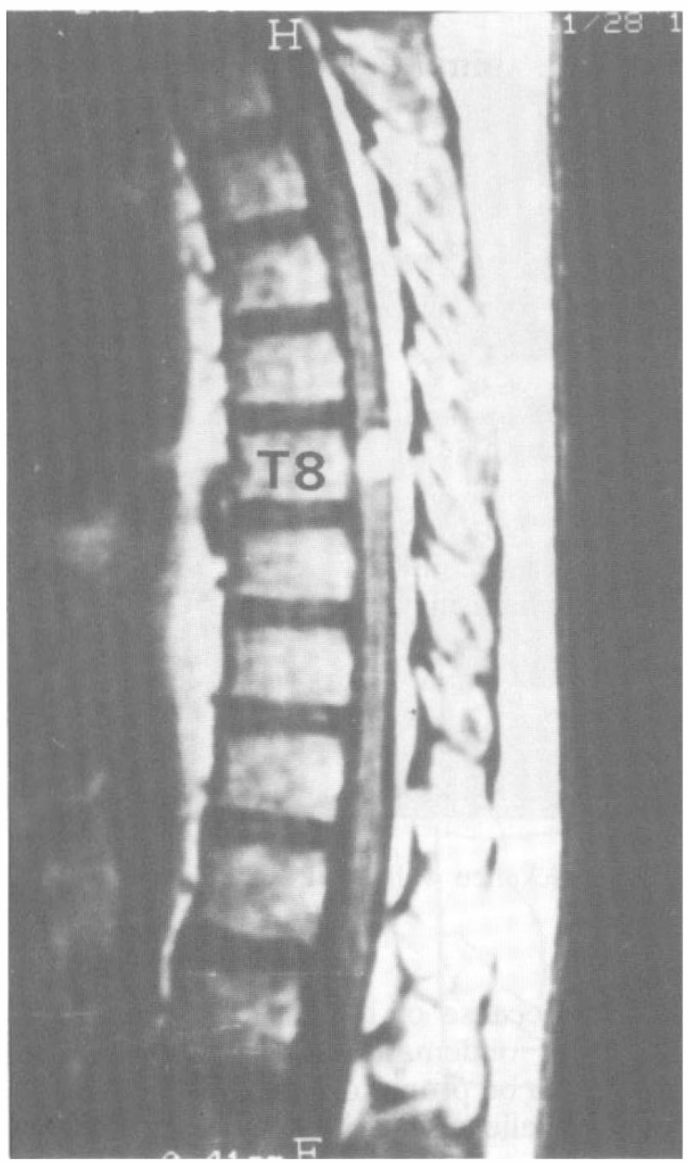

Figure 1 Sagittal T1-weighted MR images with Gd-DTPA injection demonstrates an enhancing mass at T8 vertebral body level.

The preoperative diagnosis was of an intradural extramedullary mass. T8-9 total and T10 partial (upper) laminectomies were performed. The dura was tense and was opened through a midline incision. There was no tumour associated with the right $\mathrm{T} 8$ root either intra- or extradurally. The swollen cord was pulsating with a grossly dilated coronal plexus over its dorsal aspect. When the right $\mathrm{T} 9$ root was explored extradurally a conglomerate of vessels around the root was observed. The vessels were piercing the dura in the axilla of the root. The nidus around the root was then coagulated and excised. The engorged coronal venous plexus shrank immediately. Histopathological examination of the nidus showed numerous dilated vessels with thickened walls (Fig 2).

The patient showed signs of neurological improvement during the first 5 days postopera- tively while under steroid cover, and was able to walk assisted, but the spasticity did not disappear. As the dexamethasone dose was tapered off to $1 \mathrm{mg}$ four times daily he became weaker with motor power the same as that noted on his admission examination.

Considering the possibility of the pathology diagnosed on MR scans being missed or less likely an epidural haematoma, the patient was then taken to theatre after having a repeat myelogram, which was the same as the preoperative myelogram. On reexploration, there was no haematoma, so we decided to extend the upper aspect of the exposure. A $\mathrm{T} 7$ total laminectomy was carried out, and then a midline dural incision. We found a grey purplish mass $6 \mathrm{~mm}$ in diameter over the right side of the cord. It was slightly mobile in caudal direction; it originated from the lower rootlets of the T7 root (Fig 3). The tumour was extirpated in toto.

Histopathological examination revealed a cellular neurofibroma rich in vascular components. Oval tumor cells with eosinophilic cytoplasm were arranged in bundles (Fig 4).

The postoperative period was uneventful. The spasticity disappeared and motor power improved gradually in a week. A search for neurofibromatosis proved negative. Discharged free of deficit on the 10th day, he remains symptom- and recurrence-free at 2 years postoperatively.

\section{Discussion}

Reports of patients with coexisting pathologies are rare but must be considered seriously. Discussions on these unusual cases are helpful guidelines to others so that they will not repeat similar mistakes either in the diagnosis or in the management of their patients. On the other hand, similar associations observed over time may end up creating a peculiar clinical presentation.

The challenges faced during the care of our patient reported here were two-fold. Firstly the preoperatively diagnosed spinal tumour could not be found at the appropriate level, possibly because of its slight mobility, and secondly there was a coexisting pathology distracting the attention which in fact could not be demonstrated directly with contemporary neuroimaging techniques other than spinal angiography. In view of the clinical history and the radiographical appearances, an intradural 


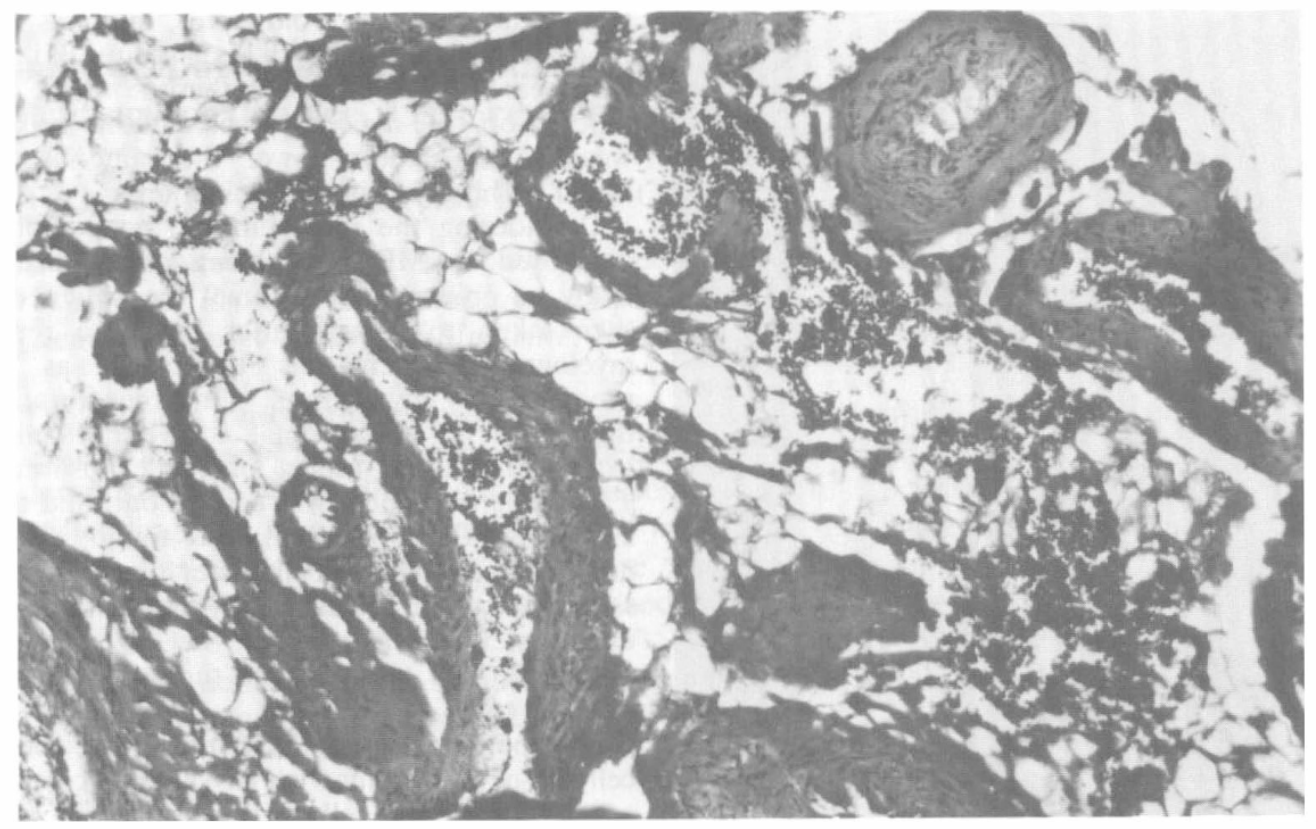

Figure 2 Photomicrograph of the dural AVF nidus. Note thickened walls of the vessels (haematoxylin and eosin $\times 115)$.

extramedullary mass at T8 level was the primary diagnosis for our case. However it should be considered that the technical and practical beauty of MR is of little help to a surgeon who is searching in the midthoracic region for a vertebra whose landmarks are obscured by drapes. ${ }^{5}$ As a part of our usual practice with midthoracic lesions, the level was marked with clips preoperatively and also checked by peroperative radiography. For this purpose a paperclip or an ordinary hypodermic needle may also be used. What actually distracted us was a vascular pathology which could have contributed to the enhancement on MR scans. Slight mobility of the neurofibroma could be another factor responsible for the initial negative exploration for a mass lesion. Mobile extramedullary tumours of the spinal cord have been reported but they most often occur at the cauda equina level, $;, 7$ but in the cases reported there was a marked discrepancy between the radiological and the surgical findings in the location of the tumour during surgery. On the other hand, we made no attempt to pass a rubber catheter either cephalad or caudad in search of the tumour, mainly because of the fact that the spinal cord was oedematous and therefore considered to be prone to injury. Nevertheless, we now believe that either a rubber catheter should have been inserted or the laminectomy should have been extended cephalad during the initial intervention.

Two histologically verified pathologies adjacent to each other as reported here confirm the fact that spinal AVF can easily be overlooked both pre- or peroperatively upon the interpretation that the congested vascularity might have been due to the tumour at a higher level. The pathophysiological basis of such an association is what deserves attention. The neurofibroma, like all spinal masses, compresses the spinal cord whereas spinal dural AVFs are low-flow shunts which cause neurological dysfunction due to venous hypertension. ${ }^{2,8-10}$ They transmsit arterial blood pressure to the venous system. The absence of valves between the coronal venous system and the radial veins facilitates the transmission of this high venous pressure to the neural tissues, which then causes congestive myelopathy. The venous efflux of a dural AVF is 


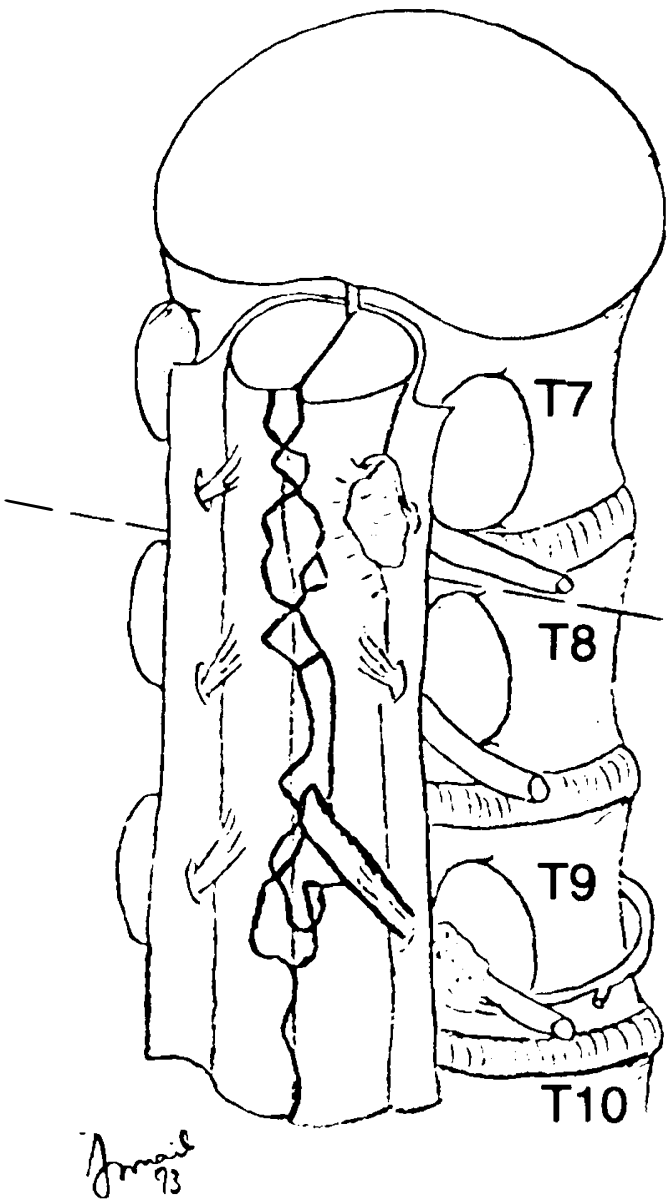

Figure 3 Illustrative description of the operative findings. Dotted line denotes the upper limit of the initial surgical intervention.

usually superiorly directed, against a greater hydrostatic pressure in the upright position. ${ }^{10.11}$ Understandably, when there is a rostral mass compressing the spinal cord as was the case in our patient, the venous drainage within the theca will be further impaired, which will then augment the ischaemia of the cord parenchyma.

The diagnosis of a thoracic pathology large enough to compress the spinal cord, ie an extraaxial tumour like a neurofibroma, is often straightforward with any of the usual diagnostic techniques. Though the diagnostic accuracy of the MR for the cervical and upper thoracic regions is higher than for the midthoracic and thoracolumbar segments, the initial disadvantages set forward as the deleterious effect of respiratory, cardiovascular and peristaltic motion have today been largely overcome by new techniques like cardiac gating or phase encoding $^{12}$ and the use of a high resolution surface coil. ${ }^{13}$ Regarding the diagnosis of a spinal AVF, myelography showing a "worm-like defect' should raise a suspicion. Of the noninvasive imaging modalities, computed tomography has so far been rather disappointing in the diagnosis of spinal dural AVF. $^{2}$ Using MR, a spinal dural AVF unlike the intramedullary $\mathrm{AVMs}^{12}$ is very difficult to visualise since the nidus is very small and is located on the dura near the intervertebral foramen., ${ }^{3,12}$ Spinal intramedullary changes associated with a spinal dural AVF were reported to appear as low signal intensity on T1- and high signal intensity areas on T2-weighted images. ${ }^{3,12-14}$ This observation is rather indirect which is basically due to the spinal cord oedema secondary to venous congestion that reverses after the obliteration of the arteriovenous shunt. ${ }^{3.14}$ Only Masaryk et al ${ }^{13}$ were able to demonstrate the spinal AVF of three patients directly as serpiginous areas of low signal around the cord outlined by high signal cerebrospinal fluid on T2-weighted images using high-resolution surface coil MR. Another recent observation was that the congested region of the cord may even enhance with delayed imaging after the administration of Gd-DTPA. ${ }^{14}$ The radiologist therefore should be guided. MR study of our case was carried out without such a close interdepartmental feedback; thus, unfortunately, the very important T2-weighted sequence was not employed at all. However, considering the fact that MR scans can usually be normal in patients with a spinal dural AVF, patients with unexplained myeloradiculopathy clearly require further diagnostic evaluation even if MR scans are normal. Thus spinal arteriography remains indispensable ${ }^{14}$ in understanding the blood flow patterns and the anatomy of dural AVFs for the foreseeable future.

The experience of Hoffman and Bagan was very similar to ours except for the fact that there was a family history of neuro- 


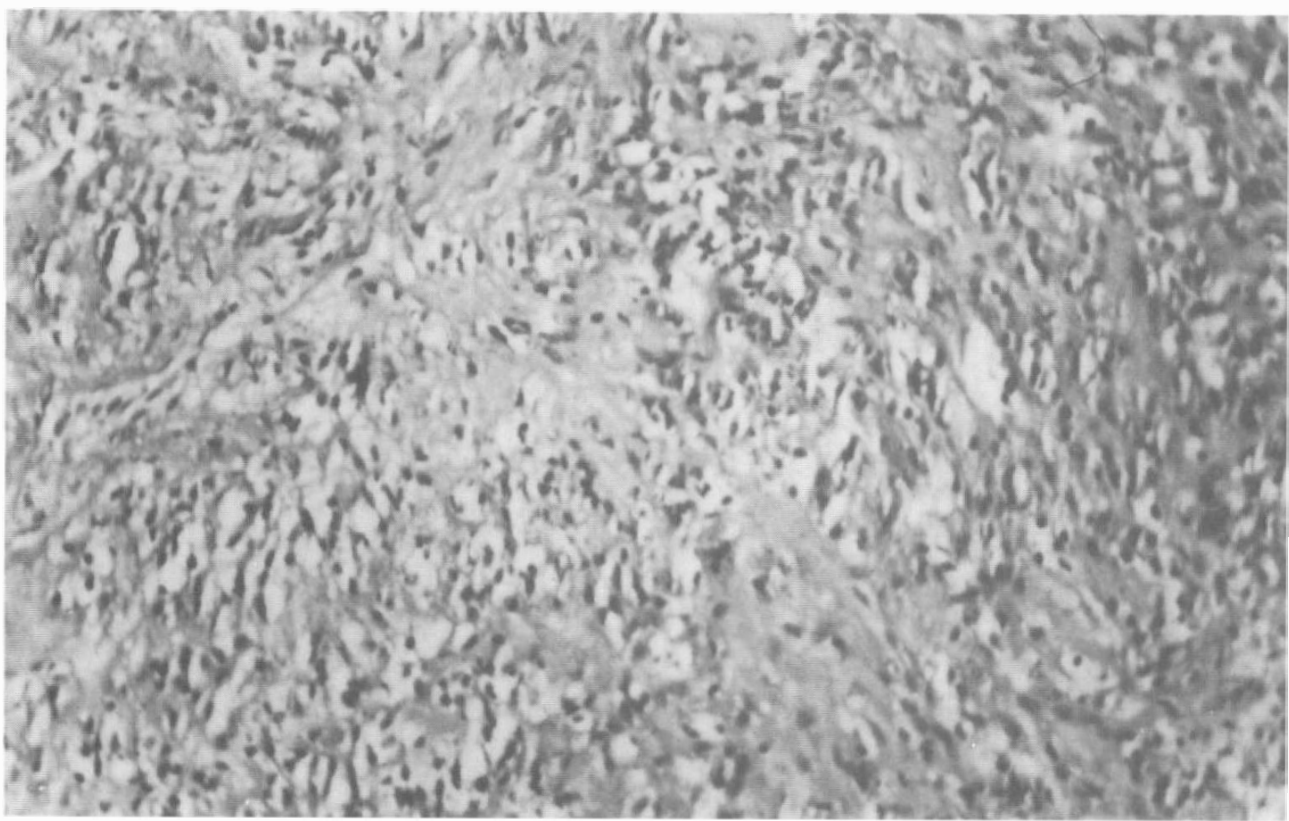

Figure 4 Photomicrograph of the neurofibroma originating from the T7 root (haematoxylin and eosin $\times 115)$.

fibromatosis. ${ }^{4}$ Their patient was a 17 year old male who harboured a neurofibroma at C2-3 and an epidural arteriovenous malformation (an AVF according to new classification) at C5-6. Biopsy of both masses resulted in brisk haemorrhage during two operations. Unfortunately their patient died during the anaesthesia induction in the third operation. The authors felt obliged to stress the importance of performing preoperative angiography in cases demonstrating myelographic findings which could have been produced by primary vascular lesions unrelated to other suspected disease processes. Only further similar reports will tell whether this is a peculiar clinical presentation of a dural AVF.

Treatment for a spinal dural AVF is no longer stripping of the coronal plexus. ${ }^{2.8}$ The extradural nidus or vessel clusters are coagulated and excised. Coagulation of the dura adjacent to the dorsal root sleeve may also cure the lesion but will make duraplasty obligatory. Complete obliteration of extradural vessels often requires transection of the nerve root. ${ }^{9}$ As for neurofibromas, the treatment of choice has always been and is their total excision, which may also necessitate the removal of the involved root or the rootlet. ${ }^{15}$

In conclusion, we have reported the case of a patient harbouring a spinal AVF adjacent to a spinal neurofibroma which may be a peculiar presentation. MRI may have to be complemented with spinal angiography to diagnose such cases. The coexistence of two common pathologies as such may be more frequent than has been detected and reported in neurosurgical practice.

\section{References}

1 Kendall BE, Logue V (1977) Spinal epidural angiomatous malformations draining into intrathecal veins. Neuroradiology 13: 181-189.

2 Yaşargil MG, Symon L, Teddy PJ (1984) Arteriovenous malformations of the spinal cord. Adv Tech Stand Neurosurg 11: 61-102. 
3 Isu T, Iwasaki Y, Akino M, Koyanagi I, Abe H (1989) Magnetic resonance imaging in cases of spinal dural arteriovenous malformation. Neurosurgery 24: 919-923.

4 Hoffman HB, Bagan M (1967) Cervical epidural arteriovenous malformation occurring with a spinal neurofibroma. Case report. J Neurosurg 37: 346-351.

5 Simeone FA (1990) Spinal cord tumors in adults. In: Youmans JR, editor. Neurological Surgery. 3rd ed. W B Saunders, Philadelphia: 3538-3539.

6 Hollin SA, Drapkin AJ, Wancier J, Huang YP (1978) Mobile schwannoma of the cauda equina. $J$ Neurosurg 48: 135-137.

7 Isu T, Iwasaki Y, Akino M, Nagashima M, Abe H (1989) Mobile schwannoma of the cauda equina diagnosed by manetic resonance imaging. Neurosurgery 25: 968-971.

8 Cahan LD, Higashida RT, Halbach VV, Hieshima GB (1987) Variants of radiculomeningeal vascular malformations of the spine. J Neurosurg 66: 333-337.

9 Oldfield EH, DiChiro G, Quindlen EA, Rieth KG, Doppman JL (1983) Successful treatment of a group of spinal cord malformations by interruption of dural fistula. J Neurosurg 59: 1019-1030.

10 Rosenblum B, Oldfield EH, Doppman JL, DiChiro G (1987) Spinal arteriovenous malformations. A comparison of dural arteriovenous fistulas and intradural AVMs in 81 patients. J Neurosurg 67: 795-802.

11 Tanaka K, Waga S, Kojima T, Furuno M, Kubo Y, Murata H (1989) Spinal dural arteriovenous malformation. Report of an unusual case. Neurosurgery 24: 915-918.

12 Di Chiro G, Doppman JL, Dwyer AJ, Patronas NJ, Knop RH, Bairamian D et al (1985) Tumors and arteriovenous malformations of the spinal cord: Assessment using MR. Radiology 156: 689-697.

13 Masaryk TJ, Ross JS, Modic MT, Ruff RL, Selman WR, Ratheson RA (1987) Radiculomeningeal vascular malformations of the spine: MR imaging. Radiology 164: 845-849.

14 Muraszko KM, Oldfield EH (1990) Vascular malformations of the spinal cord and dura. In: Winn HR, Mayberg M, editors. Neurosurgery Clinics of North America. Vol 1. W B Saunders, Philadelphia: 642-643.

15 Levy WJ, Latchaw J, Hahn JF, Sawhny B, Bay J, Dohn DF (1986) Spinal neurofibromas. A report of 66 cases and comparison with meningiomas. Neurosurgery 18: 331-334. 